\title{
On Scatterometer Ocean Stress
}

\author{
M. Portabella* AND A. StOFFELEN \\ Royal Netherlands Meteorological Institute (KNMI), De Bilt, Netherlands
}

(Manuscript received 8 June 2007, in final form 2 June 2008)

\begin{abstract}
Scatterometers estimate the relative atmosphere-ocean motion at spatially high resolution and provide accurate inertial-scale ocean wind forcing information, which is crucial for many ocean, atmosphere, and climate applications. An empirical scatterometer ocean stress (SOS) product is estimated and validated using available statistical information. A triple collocation dataset of scatterometer, and moored buoy and numerical weather prediction (NWP) observations together with two commonly used surface layer (SL) models are used to characterize the SOS. First, a comparison between the two SL models is performed. Although their roughness length and the stability parameterizations differ somewhat, the two models show little differences in terms of stress estimation. Second, a triple collocation exercise is conducted to assess the true and error variances explained by the observations and the SL models. The results show that the uncertainty in the NWP dataset is generally larger than in the buoy and scatterometer wind/stress datasets, but it depends on the spatial scales of interest. The triple collocation analysis also shows that scatterometer winds are as close to real winds as to equivalent neutral winds, provided that the appropriate scaling is used. An explanation for this duality is that the small stability effects found in the analysis are masked by the uncertainty in SL models and their inputs. The triple collocation analysis shows that scatterometer winds can be straightforwardly and reliably transformed to wind stress. This opens the door for the development of wind stress swath (level 2) and gridded (level 3) products for the Advanced Scatterometer (ASCAT) on board Meterological Operation (MetOp) and for further geophysical development.
\end{abstract}

\section{Introduction}

Wind forces motion in the ocean and in turn the motion in the ocean determines the weather and climate in large portions of the world. Wind forcing is essential in El Niño-Southern Oscillation (ENSO) and other ocean-atmosphere interaction phenomena occurring in the tropics. As such, a homogeneous wind dataset of high quality would much advance research on the prediction and mechanisms of seasonal forecasting. Vialard (2000) emphasizes that wind stress is certainly the most important forcing in the tropics. Moreover, ocean circulation and ENSO play a key role in the earth's climate. Besides tropical needs, there are other obvious

\footnotetext{
* Current affiliation: Unidad de Tecnología Marina, CSIC, Barcelona, Spain.
}

Corresponding author address: Dr. Marcos Portabella, Unidad de Techología Marina (UTM-CSIC), Pg. Marítim Barceloneta 37-49, Barcelona 08003, Spain.

E-mail: portabella@cmima.csic.es applications of such wind stress product included in the modeling of the Antarctic circumpolar current, forcing of the southern oceans, research on the variability and occurrence of storms, and forcing in complex basins, for example, the Mediterranean. A continuous wind stress time series of high temporal and spatial resolution would aid in the understanding of the unexplained yearto-year variability of these wind events.

Wind information is available from conventional platform observations, such as ship or buoy. These systems measure the atmospheric flow at a measurement height that can vary between 4 and $60 \mathrm{~m}$ and, therefore, are not a direct measure of surface 10-m wind or of stress. Stress computation requires the transformation of these winds by planetary boundary layer (PBL) parameterization schemes to represent the sea surface conditions. These PBL schemes and, in particular, the surface layer (SL) schemes embedded in the PBL schemes, have improved accuracy over the years, (Smith et al. 1992; Donelan et al. 1993; Taylor and Yelland 2001; Bourassa 2006) although they still contain transformation errors (Brown et al. 2005). 
Furthermore, buoy wind observations and, by implication, the NWP analyses that exploit these data use a fixed frame of reference. However, the wind stress depends on the difference of motion between atmosphere and ocean. Kelly et al. (2001) show that the ocean currents do produce a significant annual bias in the buoyderived wind stress estimations. In contrast, they show that scatterometer observations provide a measure of the relative motion between atmosphere and ocean and, therefore, can potentially provide accurate wind stress information.

Several authors have pointed to the mesoscale wavenumber gap in NWP wind datasets (e.g., Chelton et al. 2004; Chelton and Schlax 1996; Stoffelen 1996). This gap is caused by the sparse conventional observations at the sea surface but also aloft since NWP data assimilation systems are four-dimensional (4D) in nature and thus require 4D observations to achieve uniform quality. In fact, mesoscale atmospheric waves are poorly observed. Scatterometers, however, do have the capability to observe the surface component of the wind variability on much finer space and time scales. Moreover, scatterometers provide information on the inertial scale of ocean models and thus can potentially provide essential information to drive ocean models (e.g., Milliff 2005; Chelton et al. 2004; Chelton and Schlax 1996; Stoffelen 2008).

\section{Scatterometer wind and stress retrieval}

A scatterometer measures the electromagnetic radiation scattered back from ocean gravity-capillary waves, and it is difficult to validate quantitatively the relationship between the roughness elements associated with gravity-capillary waves and the measurements. As such, empirical techniques are employed to relate microwave ocean backscatter with geophysical variables. Since the launch of the European Remote Sensing Satellites (ERS) - ERS-1 (17 July 1991) and ERS-2 (21 April 1995)—on board the active microwave instrument (Attema 1991) operating at 5.4 GHz (C band), numerous retrieval optimizations and validation studies have been carried out. Usually the retrieved products from satellite scatterometers are validated by collocation with NWP model [e.g., European Centre for Medium-Range Weather Forecasts (ECMWF)] background winds, and/or buoy measurements (Stoffelen 1998a). A multitude of wind observations is available at a reference height of $10 \mathrm{~m}$, and scatterometer winds are traditionally related to $10-\mathrm{m}$ winds. For ERS scatterometers, the so-called CMOD5 (Hersbach et al. 2007) geophysical model function (GMF), which relates the $10-\mathrm{m}$ wind to the backscatter measurements, is used nowadays by the European Space Agency (ESA) and the Royal Netherlands Meteorological Institute (KNMI) for wind retrieval. Stoffelen (1998a) shows that for varying ocean wind conditions, the backscatter measurements vary along a well-defined conical surface in the 3D measurement space; that is, the measurements depend on two geophysical variables or a $2 \mathrm{D}$ vector. CMOD5, indeed, well explains the coherent distribution of backscatter measurements in measurement space.

Chelton et al. (2001) and Stoffelen (2002) show a high correlation between scatterometer-retrieved winds and kinematic wind stress. In fact, scatterometers respond to sea surface roughness (rather than $10-\mathrm{m}$ wind), which is closely associated with the wind stress. So, if we collocate wind stress or its equivalent value at 10-m height (hereafter referred as 10-m neutral wind) to CMOD5 winds and estimate their relationship, we would obtain a CMOD5 stress model (or CMOD5 neutral wind model) that potentially explains more of the backscatter variance than the CMOD5 wind model, since the disturbing effects of atmospheric stratification in the lowest $10 \mathrm{~m}$ have been eliminated. The GMF would provide the same conical fits in 3D measurement space, since only an argument of the CMOD function has been transformed. For example, Milliff and Morzel (2001) use a $10-\mathrm{m}$ neutral wind GMF to transform SeaWinds scatterometer winds to stress.

The aim of this paper is to define and validate a scatterometer transformation from wind speed ${ }^{1}$ to wind stress. For such purpose, triple collocations of ERS-2 scatterometer observations, moored buoy observations, and ECMWF model output are performed. Since the tropics and the extratropics have very different characteristics in terms of, for example, wind variability, atmospheric stability, or sea state, two different triple collocation datasets, one for each region, are used in this paper (see section 2).

Given the inaccuracy of the SL models (Smith et al. 1992; Taylor and Yelland 2001; Bonekamp et al. 2002), prior to transforming scatterometer wind to stress, we first take a close look at them to compare their performances. For such purpose, two of the most commonly used models-that is, the Liu, Katsaros, and Businger (LKB) model (Liu et al. 1979) and the ECMWF SL model (Beljaars 1997) - are compared in section 3, where atmospheric stability and wave age effects are analyzed in detail for a fixed geophysical dataset. The intercomparison reveals some small and interesting differences in the SL models.

\footnotetext{
${ }^{1}$ Note that the transformation only refers to wind and stress intensities, since the direction of the airflow is assumed to be constant in the SL.
} 


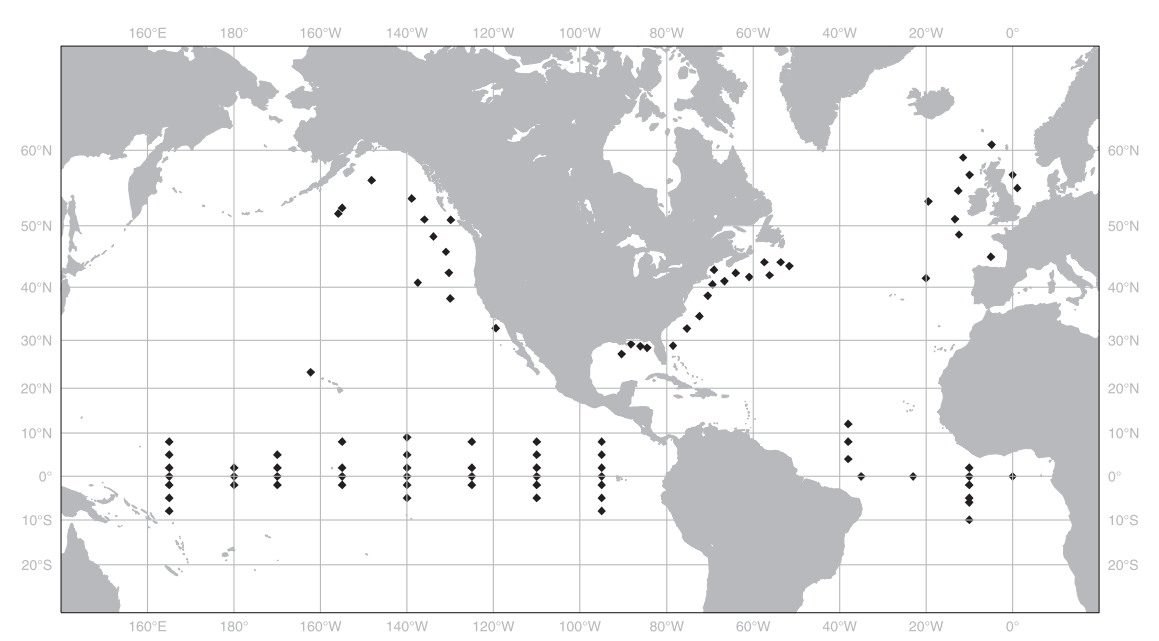

FIG. 1. Geographical location of both the tropical and the extratropical moored buoys.

Stoffelen (1998b) shows that given a triple collocation dataset, the uncertainty of the three observing systems can be uniquely determined, provided that one of the systems is used as reference for calibration (scaling) of the other two systems. In section 4, we perform the triple collocation exercise as described by Stoffelen (1998b) to assess the random error and scaling properties of both buoy and NWP wind stress derived from the SL models and to evaluate the common true variance and system error variances for winds at different heights. As such, the triple collocation exercise is used to characterize the scatterometer's ability to measure kinematic wind stress, rather than wind, and to recommend a wind-to-stress transformation for the ERS scatterometer. Finally, a summary of the work and recommendations for future developments are presented in section 5 .

\section{Data}

Two triple collocation datasets for the years 2000 (tropical data) and 1999/2000 (extratropical data) are generated to carry out the work described in this paper. The three data sources used in these datasets are the ERS-2 scatterometer, the moored buoy network, and the ECMWF model.

KNMI produces the scatterometer wind and stress products within the Ocean and Sea Ice (OSI) and Climate Monitoring (CM) Satellite Application Facilities (SAFs) of the European Organization for the Exploitation of Meteorological Satellites (EUMETSAT) and develops scatterometer wind processing software in the NWP SAF. In the framework of these SAFs, KNMI has developed an ERS scatterometer data processing
(ESDP) package for the generation of operational wind products. As such, ERS-2 ESDP (version 1.0g) 10-m winds are used in this study.

The tropical moored buoy data used correspond to the National Oceanic and Atmospheric Administration's (NOAA's) Tropical Atmosphere Ocean (TAO) and Prediction and Research Moored Array in the Atlantic (PIRATA) buoy arrays, which are located in the tropical Pacific and Atlantic Oceans, respectively (see Fig. 1; data available online at http://www.pmel.noaa. gov/tao and http://www.pmel.noaa.gov/pirata).

Because of the limited number of extratropical moored buoys available online, buoy data distributed through the Global Telecommunication System (GTS) stream, quality controlled (QC) and archived at ECMWF, and kindly provided by Jean-Raymond Bidlot are used instead. Open ocean buoy data from the National Data Buoy Center (NDBC), the Marine Environmental Data Service (MEDS), and the Met Office, which are located in the extratropical North Pacific and North Atlantic Oceans, are used (see Fig. 1). Details on the data QC can be found in Bidlot et al. (2002). Note that, because of how the GTS data are encoded, the individual wind observations are only available to the closest meters per second.

Hourly sea surface winds together with other surface layer relevant parameters, such as sea surface temperature (SST) and air temperature ( $T$ ), are retrieved from the buoy data files. Additionally, first guess (FG) 40-yr ECMWF Re-Analysis (ERA-40) lowest-level (approximately $10-\mathrm{m}$ height) winds, $T$, specific humidity $(q)$, pressure $(p)$, SST, surface pressure (sp) and Charnock parameters are retrieved from ECMWF's Meterological Archive and Retrieval System (MARS) archive. 
FG winds do not contain the observed information in the scatterometer and buoys used in the triple collocation, such that the FG error and the observed wind errors may be assumed independent.

The triple collocations are performed in the following way. The ESDP collocation software is used to spatially and temporally interpolate (linear in space and cubic in time) the 3-hourly and $1.1^{\circ}$ ERA-40 forecast data to the ERS-2 scatterometer data acquisition location and time, respectively. In our experience, interpolation errors are negligible using this scheme. Then the ECMWF-ERS dataset is collocated to the moored buoy dataset using the following criteria: only observations separated less than $25 \mathrm{~km}$ in distance and $30 \mathrm{~min}$ in time are included in the ECMWF-ERS-BUOY triple collocation dataset. This implies only one ECMWF-ERS observation (the closest) per buoy observation. In practice, most of the collocations are within $12.5 \mathrm{~km}$ and $10 \mathrm{~min}$, thus considerably reducing the collocation error, that is, uncertainty due to spatial and temporal separation between collocated observations.

Several QC procedures have been applied to this dataset. The nominal ESDP QC procedure (Stoffelen 1998a) is applied to the ERS-2 retrieved wind dataset, and only the buoy data with the "highest quality" flag are used. Moreover, a $4 \sigma$ test is performed to the triple collocated dataset as in Stoffelen (1998b). The tests are carefully designed to maintain the main shape of the wind probability density functions (PDFs).

To avoid uncertainties from unnecessary SL model height transformations, it seems appropriate to use wind datasets from a fixed height. In this respect, the ERA-40 winds used here correspond to the lowest model level, that is, about 10-m height. Since the extratropical buoy dataset contains many different buoy systems with different observation heights, a compromise between the number of buoys and the observation height spread is needed. In this paper, only buoy stations with anemometer heights between 4 and $5 \mathrm{~m}$ are considered (note that all tropical buoys have a fixed anemometer height of $4 \mathrm{~m}$ ). In total, we use data from 53 tropical buoy stations and 41 extratropical buoy stations, which produced 3471 and 3345 collocations (after quality control), respectively, over the mentioned periods.

\section{Surface layer model comparison}

Most of the equations that describe the physical balances and the turbulent budgets in the lowest $10 \%$ of the PBL — that is, the surface layer-cannot be readily solved, either because of the presence of highly nonlinear terms or the requirement for enormous in situ databases (Geernaert 1999). We can alternatively characterize the flow's dominant dynamic, geometric, and temporal scales, which involve characteristic time, space, or velocity scales, by dimensionless groups of variables. The similarity theory, first postulated by Monin and Obukov (1954), states that there exists such groups of variables that have functional relationships to the flow field and/or fluxes and that these in turn can be used to characterize the behavior of the higher-order terms of the above-mentioned equations.

The surface layer is assumed to be a constant flux layer, and it extends up to a few tens of meters above the surface. In the bulk parameterization of the similarity theory, the fluxes are determined with the transfer coefficients, which relate the fluxes to the variables measured, for example, surface wind speed $(U), T$, SST, and $q$. The bulk transfer coefficients can be determined by integrating the $U, T$, and $q$ profiles. Close to the surface, the distributions of $U, T$, and $q$ are governed by diabatic processes. As such, the wind profile can be written as (e.g., Businger 1973)

$$
u_{*}=\frac{k}{\left[\ln \left(\frac{z}{z_{0}}\right)-\psi(z / L)\right]}\left(U-U_{s}\right)
$$

where $k$ is the von Kármán constant, $u *$ is the friction velocity, $z$ is the height above the surface, $z_{0}$ is the roughness length for momentum, $\psi$ is the stability function for momentum (positive, negative, and null for unstable, stable, and neutral conditions, respectively) and $L$ is the Monin-Obukhov length, which includes the effects of temperature and moisture fluctuations on buoyancy. The wind at the surface $U_{s}$ is neglected (current effects are statistically investigated in section 4d). Similar profiles to the one in Eq. (1) are also derived for the scale temperature $\left(T_{*}\right)$ and the scale humidity $\left(q_{*}\right)$ (see Liu et al. 1979). Since stability $(z / L)$ depends on $T$ and $q$, the set of three dimensionless profiles $\left(u_{*}, T_{*}\right.$, and $\left.q_{*}\right)$ has to be solved at the same time.

Although this paper seeks for the transformation of wind to kinematic wind stress $\left(u_{*}^{2}\right)$ for scatterometers, to provide a scatterometer wind stress $(\tau)$ end product [scatterometer ocean stress (SOS)], knowledge of the air density $(\rho)$ is required; that is, $\tau=\rho u_{*}^{2}$. Air density variations can be large. However, $\rho$ error, which depends on surface pressure, air temperature, and humidity, is generally small $(1 \%-2 \%)$ and can exceptionally increase locally in cases such as cold air outflow.

To solve for $u_{*}$, the wind at certain height—among other parameters-is required, and $z_{0}$ and $L$ must be estimated [see Eq. (1)]. Once $u_{*}$ is estimated, the SL 
models can be used to compute the wind or its equivalent neutral value at any height (within the SL) just by modifying $z$ or both $\mathrm{z}$ and $L$ in Eq. (1). In other words, given a wind observation at a certain height (within the SL), we can estimate the wind and/or the neutral wind at any height, provided that we first estimate kinematic stress.

The discussion of air-sea transfer is not about the validity of the approach described above but generally about the details of parameter and function choices. As such, most SL models are based on the bulk formulation derivation [e.g., Eq. (1)], and differences among them lie in the parameterization of $L$ and/or $z_{0}$. This is the case for the two SL models used in this work, that is, the LKB and ECMWF SL models. Their similarities and differences are further discussed in the following section.

\section{a. LKB versus ECMWF: Formulation}

The LKB and ECMWF SL models present the same roughness length function (see Liu and Tang 1996 and Beljaars 1997), which is written as

$$
z_{0}=\frac{0.11 \nu}{u_{*}}+\frac{\alpha u_{*}^{2}}{g}
$$

where $\nu$ is the kinematic viscosity of the air $\left(1.5 \times 10^{-5}\right.$ $\left.\mathrm{m}^{2} \mathrm{~s}^{-1}\right), g$ is the gravitational constant of the earth $\left(9.8 \mathrm{~m} \mathrm{~s}^{-2}\right)$, and $\alpha$ is the (dimensionless) Charnock parameter (see Charnock 1955). However, the Charnock value, which is a sea state parameter, is substantially different-that is, 0.011 for LKB and around 0.018 for ECMWF SL (the latter is not a fixed value).

The same happens with the formulation of the stability function $\psi(z / L)$, which is identical for both models, but it is where the computation of the $L$ parameter (Monin-Obukhov length) differs from one another (see Liu et al. 1979 and Beljaars 1997).

The stand-alone ECMWF SL model uses as input $U, T, q, p, z, \mathrm{SST}$, surface pressure ( $\mathrm{sp}$ ), and Charnock data. Similar input is used in LKB; however, the main difference is that no Charnock input but a default value of 0.011 is used instead. If $q$ information is not available, LKB also allows relative humidity (rh) observations as input. Both SL models can solve for wind stress provided that $U, T$, and SST are available-that is, when humidity and pressure observations are not available, default values are used instead. Those values are slightly different, that is, $r h=0.8$ and $\mathrm{sp}=1013 \mathrm{hPa}$ for LKB versus $\mathrm{rh}=1$ and $\mathrm{sp}=1000 \mathrm{hPa}$ for ECMWF.

Additional differences between the two models are reported in detail in Stoffelen et al. (2006) and Portabella and Stoffelen (2007) but are found to be minor.

\section{b. LKB versus ECMWF: Results}

In this section, we present the most relevant results of comparing the LKB model against the ECMWF SL model, using the tropical and extratropical datasets described in section 2. A more detailed comparison of the two SL models can be found in Stoffelen et al. (2006) and Portabella and Stoffelen (2007).

Figure 2 shows the two-dimensional histogram of LKB estimated $u *$ versus ECMWF SL estimated $u *$ for two different extratropical input datasets: GTS buoys (Fig. 2a) and ECMWF model output (Fig. 2b). Since the two datasets contain different parameters (refer to discussion in section 2) and the two SL models allow somewhat different input (see section 3a), we use the coincident parameters ( $U, T$, and SST) for all four combinations. The results have been, therefore, produced with fixed Charnock values (default values) for both models, that is, 0.011 for LKB and 0.018 for ECMWF. As it is clearly discernible, the distribution lies close to the diagonal-it is very narrow-and the correlation is 1 , meaning that the estimated $u *$ is very similar, regardless of the SL model or the dataset used. Very similar results are found when using the tropical datasets as input (not shown). In other words, the two models show very similar stresses.

A $5 \%$ bias at high $u_{*}$ values needs to be explained, though. As described above, SL model differences must lie in the roughness length and the stability parameters. Therefore, we take a closer look at these differences.

\section{1) Roughness TERM}

Figure 3 shows the same as Fig. $2 \mathrm{~b}$ but for the $z_{0}$ parameter. Again, the correlation between the two models is striking. However, a clear difference between the two model formulations is noted. As discussed in section $3 \mathrm{a}$, the Charnock parameter is substantially different for both models, that is, 0.011 for LKB and 0.018 (default value) for ECMWF. Therefore, for very low $u *$ values - where the viscosity term [first right-hand term of Eq. (2)] is dominant-the distribution lies on the diagonal (same $z_{0}$ for both models) and for higher $u *$-where the Charnock term is dominant [second right-hand term of Eq. (2)] - the distribution is off diagonal, with a slope that is given by the ratio between the Charnock values of both models.

Looking at Figs. $2 \mathrm{~b}$ and 3, we can easily realize that to achieve such good agreement in $u_{*}$ (Fig. 2), the stability term in Eq. (2) has to compensate for the difference in the roughness term between the two models. Given that the roughness term is logarithmic, the difference between LKB roughness term and ECMWF roughness term is just a constant, that is, $\ln \left(z / z_{0}^{\mathrm{ECMWF}}\right)=\ln \left(z / z_{0}^{\mathrm{LKB}}\right)-c$, 


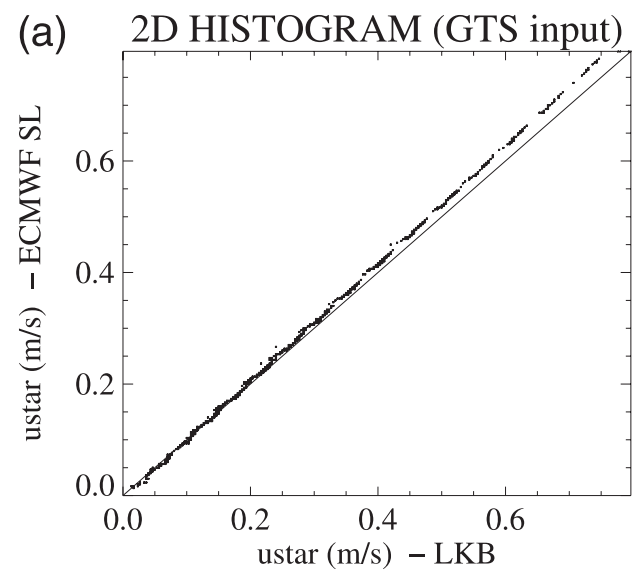

(b) 2D HISTOGRAM (ECMWF input)

$\mathrm{N}=3345$

$\mathrm{mx}=0.26999 \mathrm{my}=0.27695$

$\mathrm{m}(\mathrm{y}-\mathrm{x})=0.00696 \mathrm{~s}(\mathrm{y}-\mathrm{x})=0.00870$

cor_xy $=0.99990$

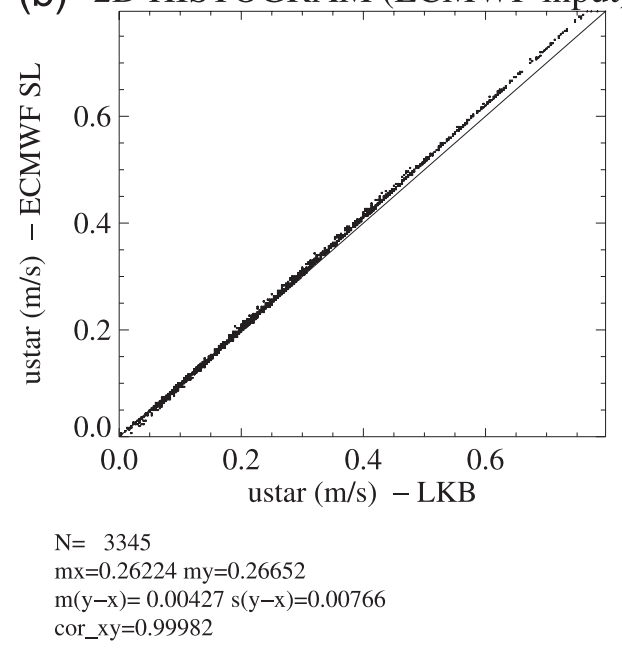

FIG. 2. Two-dimensional histogram of LKB estimated $u_{*}$ vs ECMWF SL estimated $u_{*}$ for two different extratropical input datasets: (a) GTS buoys and (b) ECMWF model output. The number of data is denoted by $N ; m x$ and $m y$ are the mean values along the $x$ and $y$ axes, respectively; $m(y-x)$ and $s(y-x)$ are the bias and the standard deviation with respect to the diagonal, respectively; and cor_xy is the correlation value between the $x$ - and $y$-axis distributions.

where $c=\ln \left(\alpha^{\mathrm{ECMWF}} / \alpha^{\mathrm{LKB}}\right) \cong 0.5$ (using the alreadymentioned LKB and ECMWF default Charnock values). Since the roughness term $\ln \left(z / z_{0}^{\mathrm{LKB}}\right)$ values vary between 13 (low $z_{0}$ ) and 9 (high $z_{0}$ ), provided that the stability term is relatively small in both models, there should be a scaling of about $5 \%$ between ECMWF and LKB $u_{*}$, which is not present at low $u_{*}$ values (see Fig. 2).

\section{2) STABILITY TERM}

The relative weight of the stability term in the denominator of Eq. (1) is analyzed for both the LKB and the ECMWF SL models. It turns out that the stability term is only relevant for low $z_{0}$ values (i.e., low winds; not shown). This is consistent with the bias observed in Fig. 2, that is, the constant $c$ becomes relevant at increasing $z_{0}$, since the stability influence becomes marginal and $\ln \left(z / z_{0}^{\mathrm{LKB}}\right)$ decreases. Moreover, the LKB stability term is more relevant than the ECMWF stability term. Since most of the observations correspond to unstable $(\psi>0)$ situations (see Fig. 4$)$, the more relevant stability term for LKB compensates the larger $z_{0}$ values from the ECMWF SL model, such that the resulting $u *$ values are very similar for both models.

Given that both SL models use the same stability functions, we can easily prove that LKB estimates larger instability (higher negative $z / L$ values) than ECMWF. Figure 4 shows the histogram of the stability parameter for both the LKB model (solid line) and the ECMWF SL model (dotted line), using the extratropical ECMWF dataset as input. We note larger accumulations at large negative $z / L$ values for LKB than for ECMWF SL, indicating larger estimated instability in the former model. Also note that the stability term is small for stable cases, since these are close to neutral stability (i.e., no cases with large, positive $z / L$ ). Similar results are found in the tropics (not shown).

\section{3) SeA State EFFects}

The Charnock parameter is a measure of wave growth, hence wave age. As mentioned in section 3a, the Charnock parameter is fixed for LKB but not for the ECMWF SL model. The Charnock parameter, as formulated in the ECMWF wave model (WAM; documentation available online at http://www.ecmwf.int/ research/ifsdocs/CY28r1/Waves/), is a function of the so-called wave-induced stress, which in turn is a function of the wind input source term (Janssen 2004). Such Charnock output is included in the collocated ECMWF dataset (see section 2) and, therefore, can be used as input to the ECMWF SL model.

Up to now, results have been produced with fixed Charnock values (default values) for both models, that is, 0.011 for LKB and 0.018 for ECMWF. To show the impact of a variable Charnock (i.e., sea state dependency) on the estimated $u_{*}$ uncertainty, we focus the analysis in the region where the sea state is most 


\section{D HISTOGRAM (ECMWF input)}

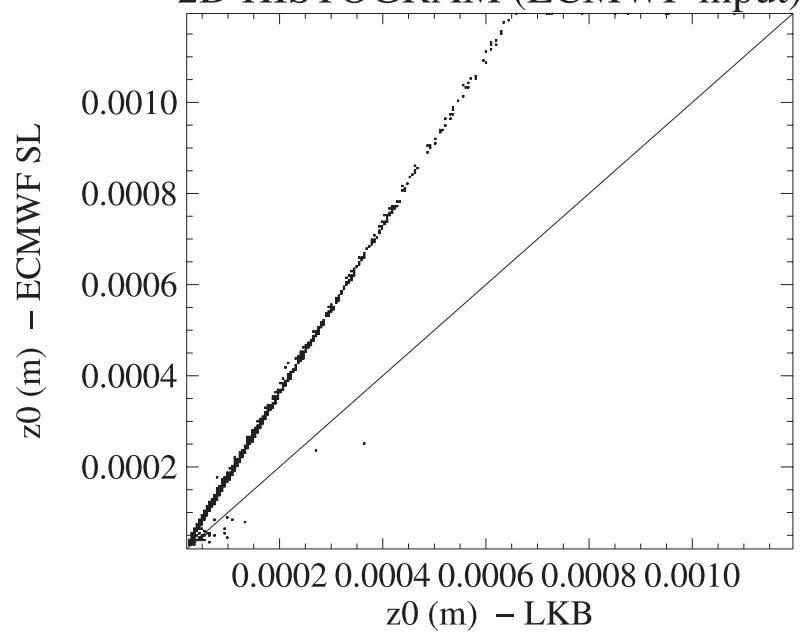

$\mathrm{N}=3345$

$\mathrm{mx}=0.00010 \mathrm{my}=0.00018$

$\mathrm{m}(\mathrm{y}-\mathrm{x})=0.00008 \mathrm{~s}(\mathrm{y}-\mathrm{x})=0.00009$

cor_xy $=0.99838$

FIG. 3. Same as in Fig. 2b, but for the estimated $z_{0}$ parameter.

relevant, that is, the extratropics (see Portabella and Stoffelen 2007). As such, Fig. 2b is reproduced with (variable) ECMWF Charnock input. The 2D histogram in Fig. 5 shows only larger spread than the one in Fig. 2b, as indicated by the different standard deviation (SD)

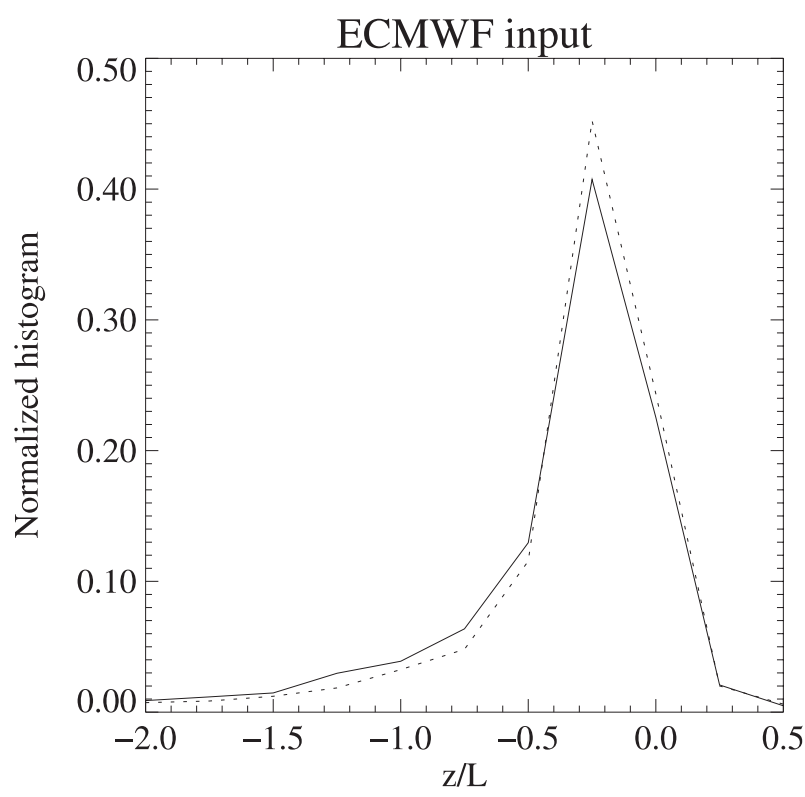

FIG. 4. Normalized histogram of $z / L$ for both the LKB model (solid line) and the ECMWF SL model (dotted line), using the extratropical ECMWF dataset as input. Negative, null, and positive $z / L$ values correspond to unstable, neutral, and stable stratification, respectively.

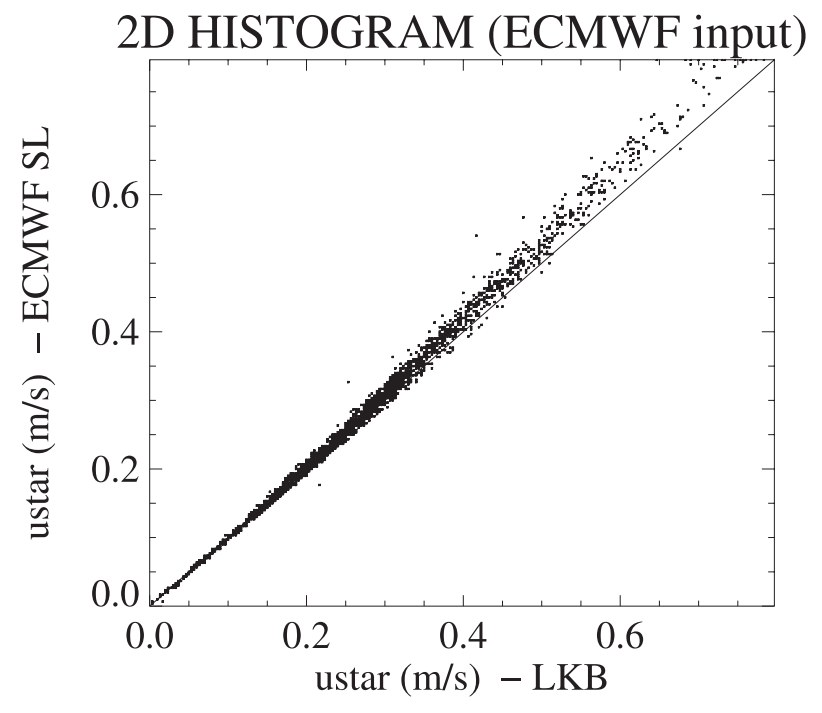

$\mathrm{N}=3345$

$\mathrm{mx}=0.26203 \mathrm{my}=0.27024$

$\mathrm{m}(\mathrm{y}-\mathrm{x})=0.00821 \mathrm{~s}(\mathrm{y}-\mathrm{x})=0.01694$

cor_xy=0.99754

FIG. 5. Same as in Fig. 2b, but with variable Charnock input to the ECMWF SL model.

scores. However, as indicated by the correlation score in Fig. 5 (very close to 1), the spread is relatively small. Even if the sea state is more relevant in the extratropics than in the tropics, it has little impact on the wind stress $\left(u_{*}\right)$ estimation.

The triple collocated dataset can be used to better analyze the Charnock output from WAM. Figure 6 shows the Charnock parameter mean value (solid curve) and SD (error bars) as a function of ERS scatterometer (left panel) and ECMWF (right panel) wind speed in the extratropics. ECMWF speeds have been converted to 4-m height speeds using the ECMWF SL model. The plots show that Charnock is highly correlated to both the scatterometer and to the ECMWF winds. As indicated by the curve slope in both plots, the Charnock correlation to both wind datasets is very similar. Note that for high winds, the error bars increase substantially mainly due to lack of data.

Figure 7 shows the scatterometer-ECMWF (Fig. 7a) and buoy-ECMWF (Fig. 7b) speed bias and SD as a function of the Charnock parameter in the extratropics. As in Fig. 6, ECMWF and GTS buoy speeds have been converted to 4-m height speeds using the ECMWF SL model. Since the scatterometer actually observes sea surface roughness, which is directly affected by the wave-induced stress, we would expect that for increasing Charnock (sea state) values, sea surface roughness and, therefore, the mean biases in the left plot would 

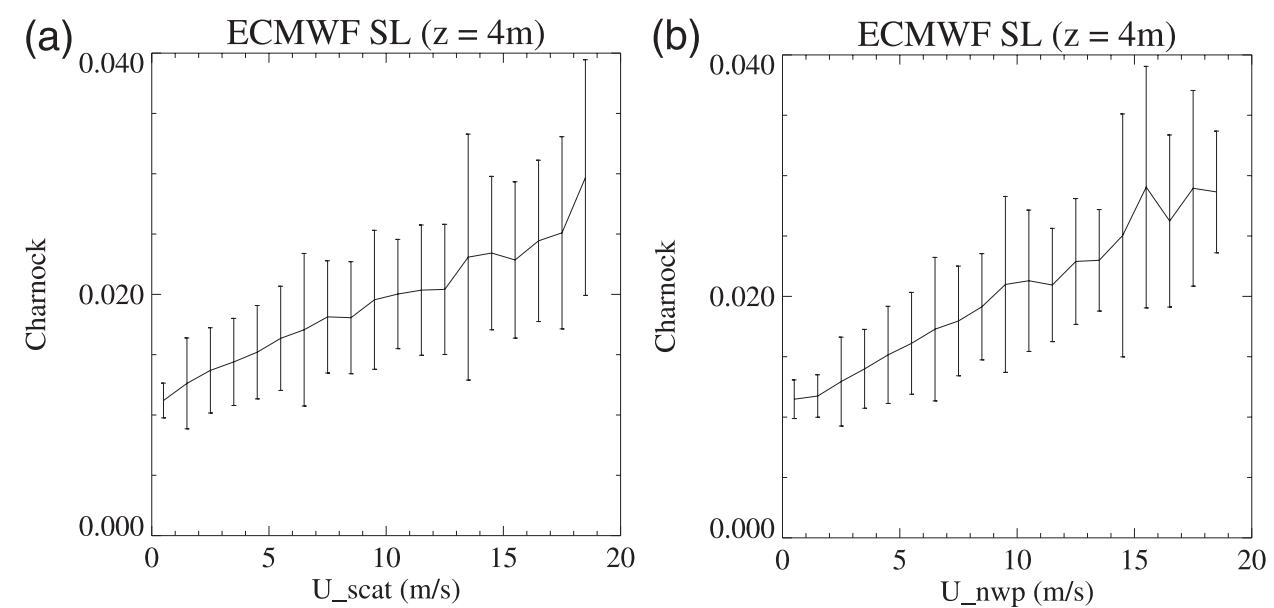

FIG. 6. Charnock parameter mean value (solid curve) and SD (error bars) as a function of (a) ERS scatterometer and (b) ECMWF wind speed (bins of $1 \mathrm{~m} \mathrm{~s}^{-1}$ ) in the extratropics.

increase. However, the bias is rather flat and very similar to the one in the right plot, where for the same set of points no explicit roughness effect is expected. Moreover, the spread in the data points could be different as a result of sea state effects, which is also not the case as the plots look very similar indeed. The wind vector cell (WVC) mean sea state roughness as observed by scatterometers thus appears mainly wind driven and cases of substantial stress-wind decoupling appear exceptional. The slight bias increase at large Charnock values in the left panel may be an indication of stress-wind decoupling, although there is not enough data to support this statement. It is, therefore, concluded that, in general, Charnock is very much correlated to the WVCmean wind (see Fig. 6) and, therefore, has a small impact on the quality of a global SOS. ${ }^{2}$ However, the Charnock parameter may contain some added value for exceptional conditions, such as cases of extreme wind variability and/or air-sea temperature difference. A much larger dataset is needed, however, to further investigate this value.

\section{4) Atmospheric STABILITY EFFECTS}

The impact of stability on wind stress estimates is often measured by the difference between the actual wind $(U)$ and its equivalent neutral wind $\left(U_{n}\right)$, that is, the wind that results from estimating $u_{*}$, given a wind observation at certain height $z$ and under certain atmospheric stability $(z / L)$, and subsequently using such $u *$ to solve Eq. (2) at the same height $z$ assuming neutral stability (i.e., $\psi=0$ ).

\footnotetext{
${ }^{2}$ Note that same conclusions are drawn when repeating the same exercise using calibrated (see section 4) scatterometer winds.
}

Figure 8 shows the difference between $U_{n}$ and $U$ as a function of $U$ using the LKB model for the tropical (left panel) and extratropical (right panel) buoy input datasets. In the tropics (Fig. 8a), differences between neutral winds and actual wind tend to increase for low winds (below $3 \mathrm{~m} \mathrm{~s}^{-1}$ ) and then slightly decrease for increasing speeds. In the extratropics (Fig. 8b), this pattern is less evident as a result of the presence of a wider range of stratification (stronger stable and unstable situations), although still present. The same pattern is produced when using ECMWF SL model instead of LKB and/or ECMWF input instead of buoy input (not shown). It is clear from Fig. 8 that stability effects are small both in the tropics and the extratropics and generally within the range $[0,0.3] \mathrm{m} \mathrm{s}^{-1}$.

\section{Wind-to-stress characterization}

In remote sensing, validation or calibration activities can only be done properly when the full error characteristics of the data are known. In practice, the problem is that prior knowledge on the full error characteristics is seldom available. Stoffelen (1998b) shows that simultaneous error modeling and calibration can be achieved by using triple collocations. Simultaneous error modeling and calibration can be used to compare triple collocation wind component datasets. In this section, the scatterometer winds are fixed in all datasets and used as reference. The two other wind-observing systems (i.e., buoys and NWP) are presented at varying heights and stability conditions, such that the true and error variances can be evaluated for the different datasets. In this way, the interpretation of the different observing systems and the performance of the SL models are characterized in this section. 

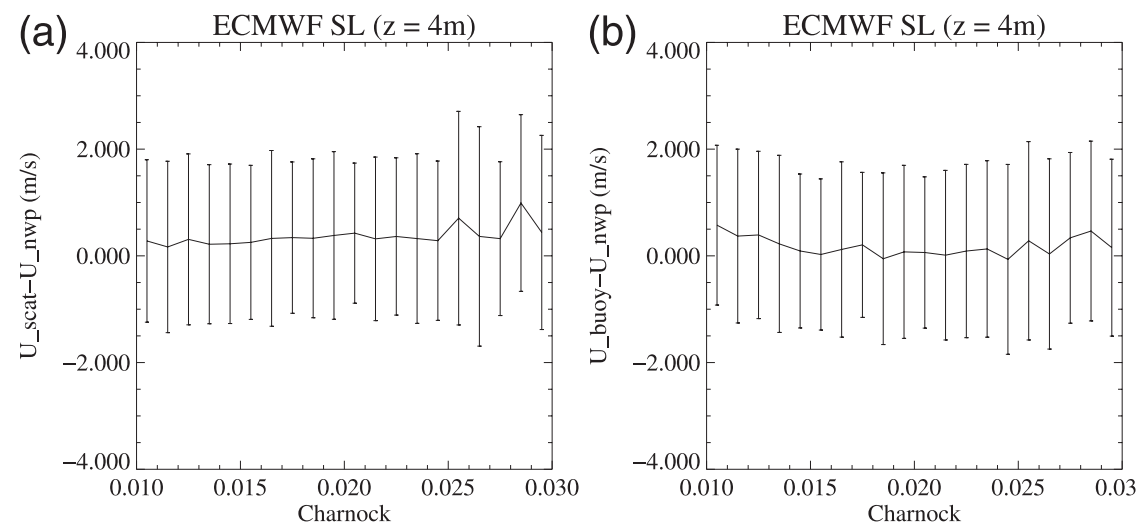

FIG. 7. (a) ERS scatterometer - ECMWF and (b) buoy - ECMWF wind speed bias (solid curve) and SD (error bars) as a function of the Charnock parameter (bins of 1) in the extratropics.

\section{a. Triple collocation exercise}

Stoffelen (1998b) shows that when the three observing systems represent the same spatial scales, the triple collocation procedure can resolve the uncertainty of the three systems, provided that one of them is used as reference for calibration. When the systems do not represent the same resolution, we have to take into account the spatial representativeness error. ${ }^{3}$ In particular, we need to make an assumption on the correlation of the spatial representativeness error, that is, the (true) variance common to the two systems that can resolve the smaller scales. ${ }^{4}$

In our case, we have one system, ECMWF, that resolves large scales (typically $>200 \mathrm{~km}$ ) and two systems that can resolve smaller scales: buoy and scatterometer. Since the scatterometer resolves wind component scales of about $50 \mathrm{~km}$, the true wind component variance on spatial scales of 50-200 km is resolved by both scatterometer and buoys but not by ECMWF (Stoffelen 1998b). For three similar observing systems to those systems used in this work [i.e., the NOAA buoy winds, the ERS scatterometer winds, and the National Centers for Environmental Prediction (NCEP) model winds], Stoffelen (1998b) estimated a correlated representativeness wind component error $\left(r^{2}\right)$ of $0.75 \mathrm{~m}^{2} \mathrm{~s}^{-2}$ in the extratropics. We assume the same $r^{2}$ value for the 50-200-km-scale true wind component variance here. In

\footnotetext{
${ }^{3}$ When comparing two observing systems with different spatiotemporal resolution, the variability of the higher-resolution system at the scales that are not resolved by the lower-resolution system may be interpreted as error, i.e., a spatial representativeness error. In fact, this variability is the resolved true variance of the higher-resolution system.

${ }^{4}$ This common variance is, in fact, the resolved true variance embedded in the representativeness error of both systems.
}

the tropics, and because of the generally lower smallscale wind variability (trade winds) with respect to the extratropics, we assume an $r^{2}$ of $0.25 \mathrm{~m}^{2} \mathrm{~s}^{-2}$.

\section{b. Error assessment using LKB and ECMWF SL models}

The triple collocation exercise is used here to assess the random errors and scaling properties of the ERS scatterometer, and buoy and ECMWF winds using ERS scatterometer CMOD5 winds as a reference system. As such, the performance of the two SL models (i.e., that is, LKB and ECMWF) compared in section 3, can be tested by using the SL models to convert buoy and ECMWF wind observations to different reference heights (e.g., 4 and $10 \mathrm{~m}$ ) and then estimating the errors of the buoy and NWP converted wind "observations."

Table 1 shows the true variability and the observation error for tropical and extratropical datasets when LKB is used to produce the (buoy and NWP) wind datasets at $10-\mathrm{m}$ height. Note that the scores are given in terms of wind vector SD (computed from wind component SD) rather than wind vector variance (square of SD value), since the former is most commonly used to refer to wind variability and observation errors. The true variability in the extratropics $\left(7.48 \mathrm{~m} \mathrm{~s}^{-1}\right)$ is comparable to the one estimated by Stoffelen (1998b; $\left.7.03 \mathrm{~m} \mathrm{~s}^{-1}\right)$ and substantially larger than the tropical values $\left(5.79 \mathrm{~m} \mathrm{~s}^{-1}\right)$. This is an expected result, since the wind variability is known to be substantially lower in the tropics than in the extratropics.

The correlated part of the representativeness error, as mentioned above, represents the common variance in the higher-resolution systems, that is, the scatterometer and the buoys. Therefore, when performing data interpretation for high-resolution applications, for example, the development of 25 - or $50-\mathrm{km}$ wind products, this 

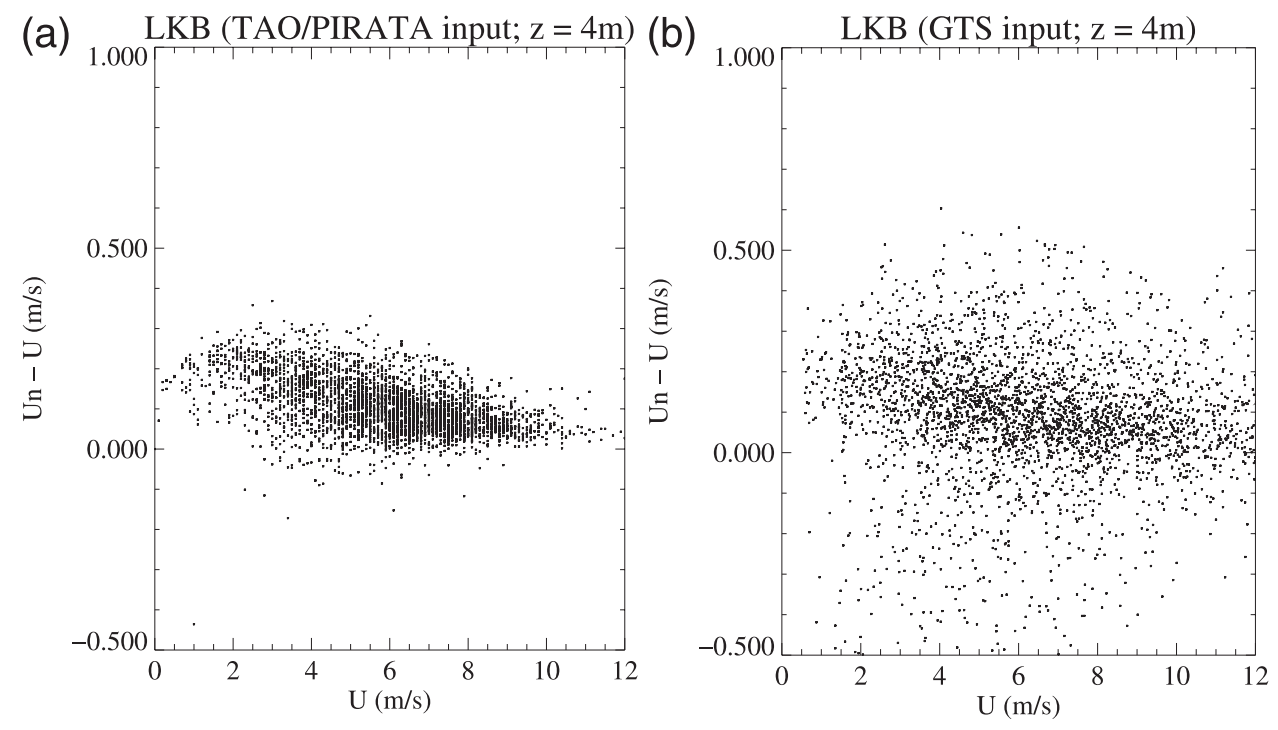

FIG. 8. Difference between the LKB estimated $U_{n}$ and $U$ as a function of $U$ for (a) TAO/PIRATA (tropics) and (b) GTS (extratropics) buoy input datasets at 4-m height. Note that points from (b) plot have been perturbed along the $x$-axis bins with a uniform distribution ranging $[-0.5,0.5] \mathrm{m} \mathrm{s}^{-1}$ to better discern the vertical distribution of points, i.e., the GTS speed binning (see section 2), otherwise it produces a concentration of points along the vertical lines.

common variance is considered as part of the true variance but also as part of the error (lack of highresolution information) of the lower-resolution system, that is, the NWP model. Table 2 provides accounts for such interpretation. On the other hand, when looking at lower-resolution applications-for example, NWP data assimilation - this common variance cannot be resolved and is, therefore, interpreted as part of the (spatial representativeness) error of the higher-resolution systems, that is, scatterometer and buoy. Note that Table 1 shows the same as Table 2, but it accounts for the latter interpretation. We also note that differences between the two tables are produced by the assumed $r^{2}$ value, which is small compared to true variance and generally modest compared to the error variances.

When the ECMWF SL model is used (instead of LKB) to produce the (buoy and NWP) wind datasets at $10-\mathrm{m}$ height, the triple collocation results (not shown) are almost identical to the ones in Tables 1 and 2, that is, the performance of both SL models is comparable.

TABLE 1. Estimates of the wind vector SD of the true distribution and the errors of the scatterometer, LKB-derived 10-m buoy and ECMWF winds for NWP-scale $(\sim 200 \mathrm{~km})$ wind in the tropics and the extratropics.

\begin{tabular}{lcccc}
\hline & True wind & Scatterometer & Buoy & ECMWF \\
\hline Tropics $\left(\mathrm{m} \mathrm{s}^{-1}\right)$ & 5.79 & 1.36 & 1.63 & 1.91 \\
Extratropics $\left(\mathrm{m} \mathrm{s}^{-1}\right)$ & 7.48 & 2.01 & 1.98 & 1.78 \\
\hline
\end{tabular}

These results are in line with the results of section 3, where both models were showing little differences. The same exercise is repeated using buoy and NWP winds at 4-m height (the approximate measurement height of buoys). In this case, no SL model transformation is required for the buoy winds. The results (not shown) are very similar in terms of true variability and errors of the different sources, denoting that the SL model does not introduce additional error when buoy winds are transformed from 4 to $10 \mathrm{~m}$. It also implies that scatterometer winds can be scaled equally well to 10- and 4-m winds.

However, when performing triple collocation, the scaling factor for buoy (i.e., the buoy-to-scatterometer wind calibration value) is closer to one at a reference height of 4 than at $10 \mathrm{~m}$, meaning that CMOD5 scatterometer winds should be interpreted as 4- winds rather than $10-\mathrm{m}$ winds.

\section{c. Scatterometer wind interpretation}

As discussed in the introduction, scatterometers are essentially observing wind stress. Therefore, we may better interpret scatterometer-derived winds as equivalent neutral winds (i.e., stress) rather than real winds.

TABLE 2. Same as in Table 1, but for 50-km-scale wind.

\begin{tabular}{lcccc}
\hline \hline & True wind & Scatterometer & Buoy & ECMWF \\
\hline Tropics $\left(\mathrm{m} \mathrm{s}^{-1}\right)$ & 5.84 & 1.17 & 1.48 & 2.04 \\
Extratropics $\left(\mathrm{m} \mathrm{s}^{-1}\right)$ & 7.58 & 1.60 & 1.55 & 2.16 \\
\hline
\end{tabular}


TABLE 3. Estimates of the wind vector SD of the true distribution and the errors of the scatterometer, LKB-derived 10-m buoy and ECMWF neutral winds for NWP-scale $(\sim 200 \mathrm{~km})$ wind in the tropics and the extratropics.

\begin{tabular}{lcccc}
\hline \hline & True wind & Scatterometer & Buoy & ECMWF \\
\hline Tropics $\left(\mathrm{m} \mathrm{s}^{-1}\right)$ & 5.79 & 1.37 & 1.64 & 1.92 \\
Extratropics $\left(\mathrm{m} \mathrm{s}^{-1}\right)$ & 7.49 & 1.97 & 2.01 & 1.78 \\
\hline
\end{tabular}

In this section, we investigate the interpretation of scatterometer data by performing the triple collocation exercise for the following two different datasets:

- ERS CMOD5 winds, buoy real winds, and ECMWF real winds; and

- ERS CMOD5 winds, buoy neutral winds, and ECMWF neutral winds.

The first dataset is the same as the one used in section $4 \mathrm{~b}$. The second dataset is the same as the first one but for buoy and NWP-converted neutral winds using either the LKB or ECMWF SL model. As in section $4 \mathrm{~b}$, ERS scatterometer CMOD5 winds are used as reference.

The true variability and error scores of dataset A (see Tables 1 and 2) are very similar to the scores obtained with dataset B (see Tables 3 and 4) when using LKB model and 10-m conversion. The same conclusions are drawn when using the ECMWF SL model and/or 4-m conversion. This indicates that scatterometer winds can explain the same true variability regardless of whether these are tested against real or neutral winds. That is, scatterometer winds are as representative of real winds as they are of equivalent neutral winds (or stress).

To reinforce such conclusion, and given the fact that CMOD5 GMF was tuned to 10-m real (NWP) winds, we develop a new GMF (CMOD5n) by tuning our CMOD5 real winds to neutral winds. Figure 9 shows the bias of CMOD5 winds with respect to $10-\mathrm{m}$ buoy real winds (solid) and 10-m buoy neutral winds (dotted) as a function of buoy wind speed. ${ }^{5}$ By subtracting these two curves [i.e., about $0.2 \mathrm{~m} \mathrm{~s}^{-1}$ in the tropics (Fig. 9a) and $0.1 \mathrm{~m} \mathrm{~s}^{-1}$ in the extratropics (Fig. 9b)], we derive a statistical real-to-neutral conversion (dashed) that can be used to derive CMOD5n from CMOD5.

We then perform the same triple collocation exercise as before but using ERS CMOD5n winds instead of CMOD5 winds in datasets $\mathrm{A}$ and $\mathrm{B}$ as a reference. As expected, the results are, again, very similar.

The fact that scatterometer winds are statistically as close to real winds as to neutral winds can be explained

\footnotetext{
${ }^{5}$ Since most of the times there is unstable stratification (see Fig. 4), the real winds are biased low with respect to the equivalent neutral winds at any reference height within the SL.
}

TABLE 4. Same as in Table 3, but for 50-km-scale wind

\begin{tabular}{lcccc}
\hline & True wind & Scatterometer & Buoy & ECMWF \\
\hline Tropics $\left(\mathrm{m} \mathrm{s}^{-1}\right)$ & 5.83 & 1.17 & 1.48 & 2.04 \\
Extratropics $\left(\mathrm{m} \mathrm{s}^{-1}\right)$ & 7.59 & 1.54 & 1.60 & 2.16 \\
\hline
\end{tabular}

as follows. On the one hand, the stability effects are small, that is, differences between real and neutral winds are subtle (see Fig. 8 in section $3 b$ ). On the other hand, SL models and the different observations (wind, SST, and air temperature) used by the models to compute height conversions and neutral winds contain errors, which in turn mask the already subtle differences between real and neutral winds (Stoffelen et al. 2006; Portabella and Stoffelen 2007).

Although scatterometer winds can be interpreted as real winds from a statistical point of view, there may be special air-sea interaction situations where the scatterometer shows its real potential to measure stress. For example, note that a difference of $0.2 \mathrm{~m} \mathrm{~s}^{-1}$ exists between neutral and real winds using the tropical dataset. The extratropical difference $\left(0.1 \mathrm{~m} \mathrm{~s}^{-1}\right)$ is smaller mainly because of cases with stable stratification that appear below the main cloud of points in Fig. 8. For these single cases, the use of stability information may increase the true variability in a triple collocation exercise, therefore indicating that such scatterometer observations should be interpreted as neutral winds (or stress) rather than real winds. To prove this, further tests with a larger dataset are required.

\section{d. Scatterometer wind-to-stress transformation}

To obtain stress, first a well-calibrated scatterometer $10-\mathrm{m}$ neutral wind is required. Then an SL model like the LKB or ECMWF SL can be used to convert 10-m neutral winds to wind stress. In fact, since the most recently developed SL models (Taylor and Yelland 2001; Bourassa 2006) have similar performance up to $16 \mathrm{~m} \mathrm{~s}^{-1}$ (Bourassa 2006), either one of them can be used to do the neutral-to-stress conversion. Because no stability information is needed to do this conversion, an independent SOS product can be developed straightforwardly.

To obtain the calibrated scatterometer 10-m neutral wind, a scatterometer-to-buoy correction (calibration) and a real-to-neutral wind conversion need to be applied to CMOD5 winds. The combined correction and conversion is represented by the dotted curves in Fig. 9, which have a different mean (absolute) value of 0.8 $\mathrm{m} \mathrm{s}^{-1}$ in the tropics (Fig. 9a) and $0.55 \mathrm{~m} \mathrm{~s}^{-1}$ in the extratropics (Fig. 9b). The latter further confirms the results from Hersbach et al. (2007) with a similar extratropical dataset. 

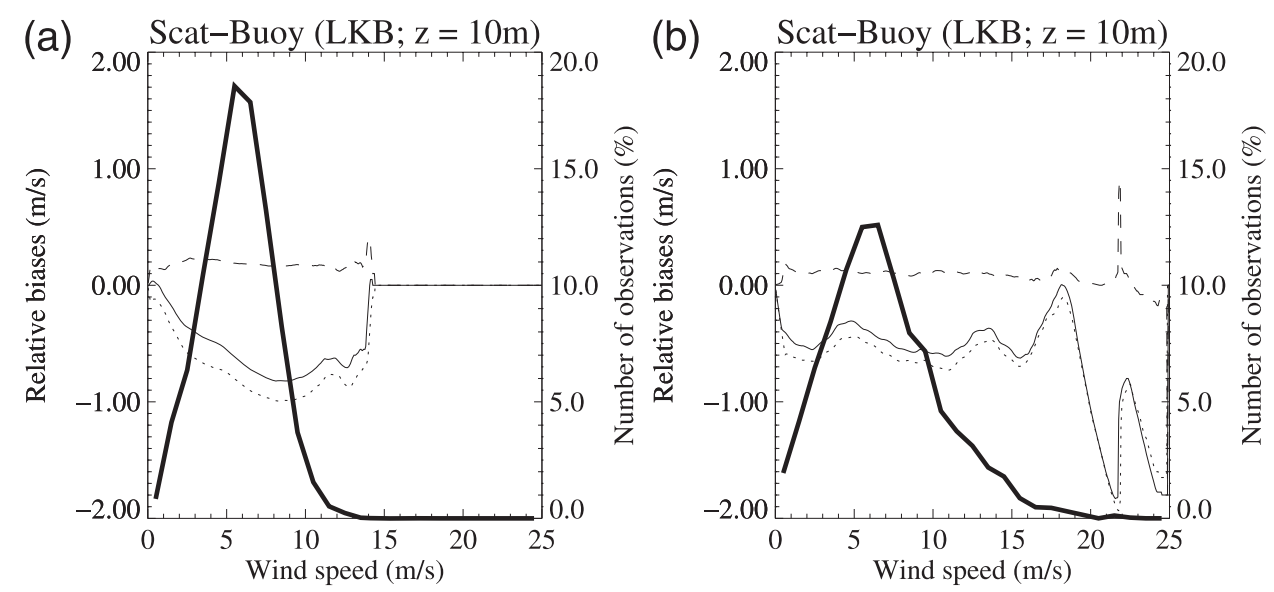

FIG. 9. Relative bias of CMOD5 winds with respect to 10-m buoy real winds (solid line) and 10-m buoy neutral winds (dotted line) as a function of buoy wind speed for the (a) tropical and (b) extratropical datasets. The buoy height conversion is performed with the LKB model. The dashed curve corresponds to the solid minus the dotted curve. The thick solid curve corresponds to the number of data.

Several effects may lead to these differences between tropical and extratropical datasets. The most relevant effects are, on the one hand, the large wind variability in the extratropics and, on the other hand, the effect of currents in the tropics. To recommend a final combined correction value, an analysis of the uncertainties of the triple collocation exercise (mainly produced by the mentioned effects) is performed. One way to analyze such uncertainties is to take the calibrated dataset (after triple collocation) and examine the residual biases buoy by buoy. As such, we compute the residual wind component (the west-east $U$ and the south-north $V$ wind components) buoy and ECMWF biases against scatterometer at each buoy location. Table 5 shows the average and $\mathrm{SD}$ of the mentioned wind component residual biases. Only buoy locations with at least 50 triple collocations-34 tropical and 30 extratropical buoy locations-are used in the statistics. The uncertainty found in the extratropics (SD of about $0.2 \mathrm{~m} \mathrm{~s}^{-1}$ ) is consistent with the expected wind variability effect. A comparable result is found for the tropical dataset, indicating that the uncertainties produced by, for example, the currents in the tropics, are comparable to the ones produced by, for example, the large wind variability in the extratropics. In other words, for a global correction both combined correction values (i.e., 0.8 $\mathrm{m} \mathrm{s}^{-1}$ found in the tropics and $0.55 \mathrm{~m} \mathrm{~s}^{-1}$ in the extratropics) have a similar degree of confidence.

Therefore, we recommend adding $0.7 \mathrm{~m} \mathrm{~s}^{-1}$ (compromise between the tropical and the extratropical values) to CMOD5 winds to obtain the scatterometer $10-\mathrm{m}$ neutral winds. To obtain real winds we recommend adding $0.5 \mathrm{~m} \mathrm{~s}^{-1}$ to CMOD5.

\section{Conclusions}

Scatterometer backscatter is closely related to ocean kinematic stress. For practical reasons, however, Cband backscatter has been related to real 10-m winds. Effects of stability, currents, and waves could then potentially cause error in the scatterometer interpretation. In this paper, we statistically investigate a physically more direct interpretation of scatterometer backscatter data as kinematic stress or as its equivalent $10-\mathrm{m}$ neutral winds.

Since direct stress or roughness measurements are generally lacking for such purpose, a tropical and an extratropical triple-collocated wind dataset are used: ERS-2 scatterometer winds, moored buoy data, and ECMWF model output. As a consequence, all comparisons are based on a fixed set of data points and uncertainties as a result of a difference in the number or

TABLE 5. Average and SD of the wind component residual biases (after wind calibration) for buoy and ECMWF winds against scatterometer winds in the tropics/extratropics.

\begin{tabular}{lcccc}
\hline & Buoy - scat. $U$ & Buoy - scat. $V$ & ECMWF - scat. $U$ & ECMWF - scat. $V$ \\
\hline Avg $\left(\mathrm{m} \mathrm{s}^{-1}\right)$ & $0.09 / 0.03$ & $-0.02 /-0.12$ & $0.21 / 0.08$ & $-0.02 /-0.06$ \\
$\mathrm{SD}\left(\mathrm{m} \mathrm{s}^{-1}\right)$ & $0.27 / 0.16$ & $0.13 / 0.24$ & $0.27 / 0.26$ & $0.22 / 0.24$ \\
\hline
\end{tabular}




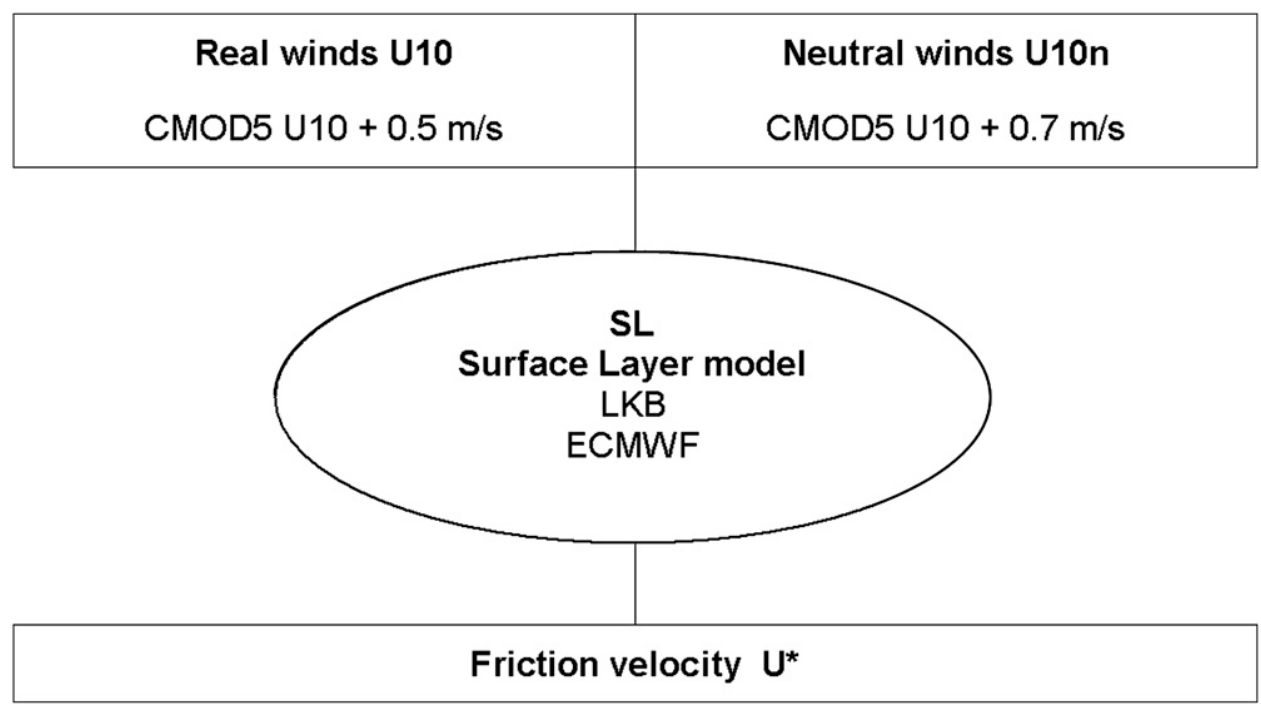

FIG. 10. Schematic of recommended scatterometer wind and stress conversion. The well-validated CMOD5 winds at 10-m height are used as basis for geophysical conversion to friction velocity. Either real or neutral 10-m winds may be transformed to friction velocity by either LKB, ECMWF, or any similar SL model.

location (e.g., by screening) of the inputs are absent. That is, the geophysical conditions for the comparisons are set fixed and a careful geophysical analysis follows.

First, a comparison between two commonly used SL models, LKB and ECMWF, is performed. The main difference between the two models is in the roughness length $\left(z_{0}\right)$ and the stability $(L)$ parameterizations. LKB uses a constant Charnock value, ECMWF uses a substantially larger Charnock value. Since the ECMWF roughness parameterization is sea state dependent, its Charnock parameter is also variable, particularly in the extratropics. However, LKB has larger instability (larger negative $z / L$ values) with respect to ECMWF. This difference actually compensates for the difference in the roughness formulation for moderate winds, such that the resulting stress values are very similar for both models. At high winds though, the stability term is much smaller than the roughness term and, therefore, the different roughness formulation results in some small stress bias (about $5 \%$ ) between the two models.

Another relevant result of this comparison is that sea state-dependent (variable Charnock) effects are small and that the atmospheric stability effects are also small and of the order of ocean current effects. Otherwise, the results show similar performance of both SL models.

To characterize the ability of scatterometers to measure stress and wind, two triple collocation exercises are performed: the first one uses scatterometer CMOD5 winds together with buoy and NWP real winds; the second one uses the same data but buoy and NWP neutral winds instead, where neutral winds are a mea- sure of the SL stress. True variability and error scores are almost identical in both exercises, meaning that scatterometer winds are as close to real winds as to neutral winds, provided that we use the appropriate scaling. A test with scatterometer neutral winds further corroborates such interpretation. An explanation for the duality in scatterometer data interpretation is that the small stability effects are masked by the uncertainty in SL models and their inputs.

The results presented in this paper confirm the ones obtained by Hersbach et al. (2007) with a similar extratropical dataset. As such, we confirm that an independent ERS scatterometer stress (SOS) product can be obtained by adding $0.7 \mathrm{~m} \mathrm{~s}^{-1}$ to CMOD5 winds and use this result as the $10-\mathrm{m}$ neutral wind input to a recently developed SL model, which is needed to compute stress. (Note that KNMI uses the LKB SL model, since it is widely used and publicly available.) A schematic illustration of the wind-to-stress conversion is shown in Fig. 10 .

The formulation of the roughness length [Eq. (3)] presented by these two SL models is not the only one available. Differences between different formulations have been thoroughly studied. For example, Bonekamp et al (2002) claim that a wave age-dependent Charnock SL model (such as ECMWF) is marginally better than a constant Charnock model (such as LKB). Moreover, several authors have proposed different wave agedependent parameterizations, for example, Donelan (1990), Maat et al. (1991), Smith et al. (1992), Johnson et al. (1998), and Drennan et al. (2003). On the other 
hand, Taylor and Yelland (2001) proposed an alternative wave steepness parameterization of $z_{0}$. The work presented in section 4 could be used to compare the performance of additional SL models in interpreting scatterometer measurements.

However, in general, SL model differences in terms of wind stress magnitude are small for winds below 10 $\mathrm{m} \mathrm{s}^{-1}$, and it is only well above $10 \mathrm{~m} \mathrm{~s}^{-1}$ that the different roughness formulations produce large differences in the estimated stress (see also Taylor et al. 2001). Moreover, according to Bourassa (2006), the most recently developed SL models (e.g., Taylor and Yelland 2001; Bourassa 2006) have similar performance up to 16 $\mathrm{m} \mathrm{s}^{-1}$, which is consistent with the comparison of LKB and ECMWF SL models performed in here. However, cases of extreme wind variability or air-sea temperature difference may show large wind and stress discrepancies. The triple-collocated datasets used in this paper are not sufficient to properly investigate the performance of the SL models in such extreme cases, where the differences between models may be more significant. As such, a study over a much larger dataset is recommended for such purposes. Moreover, it would also be interesting to study the ability of scatterometers to measure stress in such extreme conditions.

Although the results in this paper relate to the ERS scatterometer, the wind-to-stress conversion also applies to other scatterometers. A new C-band scatterometer, that is, the Advanced Scatterometer [(ASCAT) on board the Meteorological Operational satellite MetOp], which has more than twice the coverage of the ERS scatterometer, was launched on 19 October 2006. In the framework of a collaboration between NOAA and EUMETSAT, ASCAT underflights have been planned during the NOAA 2007 winter storm and tropical cyclone campaigns. These extreme weather datasets could, therefore, be used for the above-mentioned purposes.

Acknowledgments. Special thanks go to JeanRaymond Bidlot and ECMWF for providing the GTS buoy dataset (already quality controlled) together with feedback on the collocation exercise and our results. We acknowledge the help and collaboration of our colleagues working at KNMI, and specifically the people from the scatterometer group. This work is funded by the European Organization for the Exploitation of Meteorological Satellites (EUMETSAT) Climate Monitoring (CM) and Ocean and Sea Ice (OSI) Satellite Application Facilities (SAFs), led by the Deutscher Wetterdienst (DWD) and Météo-France, respectively. The software used in this work was developed at KNMI, through the EUMETSAT OSI and numerical weather prediction (NWP) SAFs, and at ECMWF. We greatly appreciate the three reviewers who helped to improve this paper.

\section{REFERENCES}

Attema, E. P. W., 1991: The active microwave instrument on board the ERS-1 satellite. Proc. IEEE, 79, 791-799.

Beljaars, A. C. M., 1997: Air-sea interaction in the ECMWF model. Proc. Seminar on Atmosphere-Surface Interaction, Reading, United Kingdom, ECMWF, 33-52.

Bidlot, J.-R., D. J. Holmes, P. A. Wittmann, R. Lalbeharry, and H. S. Chen, 2002: Intercomparison of the performance of operational ocean wave forecasting systems with buoy data. Wea. Forecasting, 17, 287-310.

Bonekamp, H., G. J. Komen, A. Sterl, P. A. E. M. Janssen, P. K. Taylor, and M. J. Yelland, 2002: Statistical comparisons of observed and ECMWF modelled open ocean surface drag. J. Phys. Oceanogr., 32, 1010-1027.

Bourassa, M. A., 2006: Satellite-based observations of surface turbulent stress during severe weather. Atmosphere-Ocean Interactions, Volume 2, W. Perrie, Ed., Advances in Fluid Mechanics, Vol. 39, WIT Press, 35-52.

Brown, A. R., A. C. M. Beljaars, H. Hersbach, A. Hollingsworth, M. Miller, and D. Vasiljevic, 2005: Wind turning across the marine atmospheric boundary layer. Quart. J. Roy. Meteor. Soc., 131, 1233-1250, doi:10.1256/qj.04.163.

Businger, J. A., 1973: Turbulent transfer in the atmospheric surface layer. Workshop on Micrometeorology, D. H. Haugen, Ed., Amer. Meteor. Soc., 67-100.

Charnock, H., 1955: Wind stress on a water surface. Quart. J. Roy. Meteor. Soc., 81, 639-640.

Chelton, D. B., and M. G. Schlax, 1996: Global observations of oceanic Rossby waves. Science, 272, 234-238.

-, and Coauthors, 2001: Observations of coupling between surface wind stress and sea surface temperature in the eastern tropical Pacific. J. Climate, 14, 1479-1498.

_- M. G. Schlax, M. H. Freilich, and R. F. Millif, 2004: Satellite measurements reveal persistent small-scale features in ocean winds. Science, 303, 978-983.

Donelan, M. A., 1990: Air-sea interaction. Ocean Engineering Science, B. Le Méhauté and D. M. Hanes, Eds., The Sea Series, Vol. 9, John Wiley, 239-292.

— , F. W. Dobson, S. D. Smith, and R. J. Anderson, 1993: On the dependence of sea surface roughness on wave development. J. Phys. Oceanogr., 23, 2143-2149.

Drennan, W. M., H. C. Graber, D. Hauser, and C. Quentin, 2003: On the wave age dependence of wind stress over pure wind seas. J. Geophys. Res., 108, 8062, doi:10.1029/2000JC000715.

Geernaert, G. L., 1999: Theory of air-sea momentum, heat and gas fluxes. Air-Sea Exchange: Physics, Chemistry, and Dynamics, G. L. Geernaert, Ed., Kluwer Academy Publishers, 25-48.

Hersbach, H., A. Stoffelen, and S. de Haan, 2007: The improved C-band ocean geophysical model function: CMOD-5. J. Geophys. Res., 112, C03006, doi:10.1029/2006JC003743.

Janssen, P., 2004: The Interaction of Ocean Waves and Wind. Cambridge University Press, 300 pp.

Johnson, H. K., J. Højstrup, H. J. Vested, and S. E. Larsen, 1998: On the dependence of sea surface roughness on wind waves. J. Phys. Oceanogr., 28, 1702-1716.

Kelly, K. A., S. Dickinson, M. J. McPhaden, and G. C. Johnson, 2001: Ocean currents evident in satellite wind data. Geophys. Res. Lett., 28, 2469-2472.

Liu, W. T., and W. Tang, 1996: Equivalent neutral wind. Jet Propulsion Laboratory Tech. Rep. 96-17, 22 pp. 
_, K. B. Katsaros, and J. A. Businger, 1979: Bulk parameterization of air-sea exchanges of heat and water vapor including the molecular constraints at the interface. J. Atmos. Sci., 36, 1722-1735.

Maat, N., C. Kraan, and W. A. Oost, 1991: The roughness of wind waves. Bound.-Layer Meteor., 54, 89-103.

Milliff, R. F., 2005: Forcing global and regional ocean numerical models with ocean surface vector winds from spaceborne observing systems. Satellite Application Facility (SAF) Training Workshop: Second Workshop on Ocean and Sea Ice, EUMETSAT Rep. P.45, 8 pp.

, and J. Morzel, 2001: The global distribution of the timeaverage wind stress curl from NSCAT. J. Atmos. Sci., 58, $109-131$.

Monin, A. S., and A. M. Obukov, 1954: Basic regularity in turbulent mixing in the surface layer of the atmosphere. $\mathrm{Tr}$. Geofiz. Inst., Akad. Nauk SSSR, 24, 163-187.

Portabella, M., and A. Stoffelen, 2007: Development of a global scatterometer validation and monitoring. EUMETSAT Ocean and Sea Ice SAF Scientific Rep. SAF/OSI/CDOP/ KNMI/SCI/RP/141, 37 pp.

Smith, S. D., and Coauthors, 1992: Sea surface wind stress and drag coefficients: The HEXOS results. Bound.-Layer Meteor., 60, 109-142.

Stoffelen, A., 1996: Error modeling of scatterometer, in-situ, and ECMWF model winds: A calibration refinement. KNMI Tech. Rep. 193, 44 pp. 1998a: Scatterometry. Ph.D. thesis, University of Utrecht, $195 \mathrm{pp}$.

_ 1998b: Error modeling and calibration: Towards the true surface wind speed. J. Geophys. Res., 103 (C4), 7755-7766.

, 2002: Scatterometer Ocean Stress. Proposal to the CM-SAF, KNMI, 12 pp. [Available online at http://www.knmi.nl/ scatterometer/.]

- 2008: Scatterometer applications in the European Seas. Remote Sensing of the European Seas, V. Barale and M. Gade, Eds., Springer, 269-282.

A., G. J. van Oldenborgh, J. de Kloe, M. Portabella, and A. Verhoef, 2006: Development of a scatterometer ocean stress product. EUMETSAT Climate Monitoring SAF Rep., 66 pp.

Taylor, P. K., and M. J. Yelland, 2001: The dependence of sea surface roughness on the height and steepness of the waves. J. Phys. Oceanogr., 31, 572-590.

,-- , and E. C. Kent, 2001: On the accuracy of ocean winds and wind stress. Extended Abstracts, WCRP/SCOR workshop on Intercomparison and Validation of Ocean-Atmosphere Flux Fields, WCRP Rep. 115, World Climate Research Programme (WCRP) and Scientific Committee on Ocean Research (SCOR), 4 pp.

Vialard, J., 2000: Seasonal forecast and its requirements for satellite products. Ocean and Sea Ice SAF Training Workshop, EUMETSAT Rep. P27, 137-143. 